\title{
Neurotoxic effects of $n$-hexane on the human central nervous system: evoked potential abnormalities in n-hexane polyneuropathy
}

\author{
YANG-CHYUAN CHANG \\ From the Department of Neurology, National Taiwan University Hospital, Taipei, Taiwan
}

SUMMARY An outbreak of n-hexane polyneuropathy as a result of industrial exposure occurred in printing factories in Taipei area from December 1983 to February 1985. Multimodality evoked potentials study was performed on 22 of the polyneuropathy cases, five of the subclinical cases, and seven of the unaffected workers. The absolute and interpeak latencies of patterned visual evoked potential (pVEP) in both the polyneuropathy and subclinical groups were longer than in the normal controls. The pVEP interpeak amplitude was also decreased in the polyneuropathy cases. Brainstem auditory evoked potentials (BAEP), showed no difference of wave I latency between factory workers and normal controls, but prolongation of the wave I-V interpeak latencies was noted, corresponding with the severity of the polyneuropathy. In somatosensory evoked potentials (SEPs), both the absolute latencies and central conduction time (CCT) were longer in subclinical and polyneuropathy cases than in the unaffected workers and normal controls. From this evoked potentials study, chronic toxic effects of n-hexane on the central nervous sytem were shown.

Outbreaks of toxic neuropathy attributable to nhexane have been described in industrial workers in Italy, Japan, Morocco, France and the United States. ${ }^{12}$ The industrial cases commonly occur in factories with inadequate ventilation and high air levels of $n$-hexane. ${ }^{1}$ Clinically, the patients present with chronic or subacute sensorimotor polyneuropathy.

In human sural nerve biopsies ${ }^{12}$ and experimental animals, ${ }^{1}$ it has been found that $\mathrm{n}$-hexane can induce axonal swelling with myelin changes in the peripheral nerves. Similar pathological changes involving the terminal portion of axons in the central nervous system has been reported in experimental animals. ${ }^{3-5}$ Clinical evidence, however, suggesting chronic neurotoxic effect of $n$-hexane on the central nervous system has rarely been mentioned in patients with $n$ hexane polyneuropathy. ${ }^{156-8}$ In the present study,

Presented in part at the 13th World Congress of Neurology (5 September 1985, Hamburg).

Address for reprint requests: Yang-Chyuan Chang, MD, Department of Neurology, National Taiwan University Hospital, Taipei, Taiwan 100.

Received 14 January 1986 and in revised form 4 June 1986. Accepted 19 June 1986 evoked potential abnormalities in patients with nhexane polyneuropathy are reported, the electrophysiological abnormalities being considered as related to the chronic neurotoxic effects of $n$-hexane on the central nervous system.

\section{Materials and methods}

\section{Materials}

From December 1983 to February 1985, an outbreak of toxic polyneuropathy was found in the printing industry near the Taipei area in Taiwan. After detailed epidemiological studies including analysis of bulk cleaning solvents used and one-hour personal air samples, questionnaire interviews on the working circumstances, and medical examinations on these patients had been carefully performed, it was found that the endemic neurological abnormalities were attributable to chronic $n$-hexane poisoning. ${ }^{9}$ Use of solvents with high contents of $n$-hexane, poor ventilation, and the habit of sleeping in the factories between shifts were important aetiological factors. ${ }^{9}$

There were 28 polyneuropathy patients. Clinically, they presented with progressive weakness and muscle atrophy, symmetrically involving the distal part of the lower extremities. In severe cases, the motor effects also involved the proximal portion of the lower limbs and the upper limbs. Subjective sensory symptoms such as numbness and paraesthesia were noted in one-third of the patients.

Among the 28 polyneuropathy cases, 22 patients under- 
Table 1 Neurological manifestations in n-hexane polyneuropathy

Number

Peripheral nervous system manifestations (in 22 patients)

Weakness in the lower extremities

Weakness in the upper extremities

Absent and/or decreased achilles reflex

Absent and/or decreased patellar reflex

Absent and/or decreased brachioradialis reflex

Absent and/or decreased biceps brachii reflex

Decreased vibration sense in the lower extremities

Hypalgesia in the lower extremities

Hypalgesia in the upper extremities

Optic nerve manifestations (44 eyes in 22 patients)

Optic or retrobulbar neuritis

Optic atrophy

Deschromatopsia (by colour plate screening test)

Visual acuity at $20 / 50$

Visual acuity at $20 / 33$

Visual acuity at $20 / 25$

Visual acuity at $20 / 20$

Visual acuity at $20 / 15$

Central nervous system manifestations (in 22 patients)

Headache and/or dizziness

Mental changes

Sleep disorder

EEG abnormalities (examined in 6 patients)

22
11
22
22
15
8
15
7
7

22
11
22
22
15
8
15
7
7
0
0
2
1
2
12
16
13
0
0
0
0

went evoked potential study. Their neurological manifestations are listed in table 1 . None of them complained of headache or dizziness. No mental changes were found on clinical mental status examination. Electroencephalography in six of 22 patients revealed normal tracings. Five subclinical cases and seven unaffected workers were also included in this study. They came from the same factories and performed similar work. In subclinical cases, there were neither neurological symptoms nor signs related to any peripheral nerve lesion, yet at least one abnormal nerve conduction velocity was seen in each case. Workers who had no symptoms and signs related to any peripheral nerve lesion, or abnormal nerve conduction velocities were classified as unaffected workers. The mean peripheral nerve conduction velocities in these groups are listed in table 2.

In the polyneuropathy cases, the age ranged from 17 to 34 years with a mean of $23.1 \pm 5.6$ years. The mean age in the subclinical cases was $23.2 \pm 7 \cdot 5$ years, with a range from 18 to 32 years. A mean age of $28 \cdot 3 \pm 6 \cdot 2$ years and a range from 20 to 36 years were found in the unaffected workers. There was one female subject in each group.
Patterned visual evoked potentials ( $p V E P s$ )

Patterned visual evoked potentials were studied with a Nicolet Pathfinder II machine (Nicolet Biomedical Instrument), recorded from the scalp by silver/silver chlorided cup electrodes. The active electrode was placed at $\mathrm{Oz}$ with a reference at $\mathrm{Cz}$ in the 10-20 system. The low- and high-frequency filters of the amplifier were set at 1 and $100 \mathrm{~Hz}$. The analysis time was 250 ms. Two hundred and fifty-six responses were averaged. For ensuring the reliability and reproducibility of the findings, the pVEP was performed twice at any given visual angle. Each eye was tested separately. The visual stimulation was generated through a NIC-1005 black-and-white checkerboard patterned reversal visual stimulator at a reversal rate of $1 \cdot 88 / \mathrm{s}$, with checks subtending $1^{\circ}, 30^{\prime}, 15^{\prime}$, and $7 \cdot 5^{\prime}$ of the visual angles. The full stimulus field size was $16^{\circ}$.

The N1 (N75), P1 (P100), and N2 (N135) latencies of the pVEPs obtained with a visual angle of $30^{\prime}$ were measured. The amplitude measurements were referred to the N1-P1 and P1-N2 interpeak amplitudes.

The normal controls for patterned VEP consist of 22 males, with a mean age of $33.1 \pm 7.9$ years.

Table 2 Nerve conduction velocities $(\mathrm{m} / \mathrm{s})$ in workers exposed to n-hexane

\begin{tabular}{|c|c|c|c|c|}
\hline & $\begin{array}{l}\text { Lahoratory } \\
\text { norms }\end{array}$ & $\begin{array}{l}\text { Unaffected workers } \\
(n=14)\end{array}$ & $\begin{array}{l}\text { Subclinical cases } \\
(n=10)\end{array}$ & $\begin{array}{l}\text { Polyneuropathy } \\
\text { cases }\end{array}$ \\
\hline $\begin{array}{l}\text { Median MNCV } \\
\text { Ulnar MNCV } \\
\text { Peroneal MNCV } \\
\text { Tibial MNCV } \\
\text { Median SNCV } \\
\text { Ulnar SNCV } \\
\text { Sural SNCV }\end{array}$ & $\begin{array}{l}61.2 \pm 5.8 \\
59.9 \pm 7.2 \\
53.4 \pm 6.1 \\
49.1 \pm 5.2 \\
56.1 \pm 4.8 \\
52.4 \pm 4.6 \\
50.3 \pm 4.7\end{array}$ & $\begin{array}{l}57.0 \pm 3.5 \\
55.4 \pm 5.0 \\
49.1 \pm 4.2 \\
46.2 \pm 4.1 \\
56.0 \pm 5.3 \\
52.1 \pm 4.7 \\
48.9 \pm 4.1\end{array}$ & $\begin{array}{l}50.6 \pm 6.1 \\
45.6 \pm 2.3 \\
41.2 \pm 5.2 \\
42.7 \pm 3.8 \\
50.3 \pm 3.3 \\
45.7 \pm 3.6 \\
46.2 \pm 2.8\end{array}$ & $\begin{array}{l}43.3 \pm 6.8(n=42) \\
40.9 \pm 5.0(n=42) \\
34.0 \pm 5.0(n=42) \\
35.9 \pm 5.6(n=42) \\
47.7 \pm 3.1(n=40) \\
44.2 \pm 4.6(n=37) \\
43.1 \pm 3.8(n=26)\end{array}$ \\
\hline
\end{tabular}

Notes:

1. MNCV = motor nerve conduction velocity; SNCV = sensory nerve conduction velocity.

2. The results were calculated by combining the findings obtained from the nerves in the right side and those in the left side.

3. Absence of evoked muscle response or sensory action potential was excluded from calculation. 
Brainstem auditory evoked potentials (BAEPs)

Brainstem auditory evoked potential data were collected, averaged, and analysed on a Pathfinder II machine. The auditory stimulus in both condensation and rarefaction polarities consisted of $100 \mu$ s clicks presented at a rate of $11 \cdot 1 / \mathrm{s}$. The intensity of the click stimulus was $60 \mathrm{~dB}$ above threshold for each subject, while a white masking noise at a level of $-40 \mathrm{~dB}$ was applied on the contralateral nonstimulating ear. For each trial, 2048 responses were averaged. Each ear was tested separately and at least twice for ensuring reproducibility and reliability. Silver/silver chlorided cup electrodes were attached at vertex $(\mathrm{Cz}$, as the positive electrode) and each mastoid (A1, A2). The electrode resistance was kept lower than $3 \mathrm{kohm}$. Filter settings were at 150 and $3000 \mathrm{~Hz}$. The analysis time was $10 \mathrm{~ms}$. All subjects were tested in the supine position on a bed.

Absolute latencies were measured from stimulus to the positive peaks. Out of the seven peaks, the asolute latencies of peaks I, III, and V were used. For determination of the central conduction time in the auditory pathway, interpeak latencies (IPLs) between peaks I-III, III-V, and I-V were measured.

In the normal controls, there were 25 males with the mean age of $32.8 \pm 9.5$ years.

\section{Somatosensory evoked potentials (SEPs)}

Three averaging channels for somatosensory evoked potentials were used to record simultaneously scalp SEPs, neck SEPs, and brachial plexus potentials by stimulation of the median nerve. The analysis time was $50 \mathrm{~ms}$.

For scalp SEPs, the active electrode was placed on either the left or right central region of the scalp (C3 or C4) contralateral to the side of median nerve stimulation. The bandpass was set at 1 and $3000 \mathrm{~Hz}$. For neck SEPs the active electrode was attached at the 7th cervical spinous process and the filter settings were 5 and $3000 \mathrm{~Hz}$. The brachial plexus potentials were recorded at the Erb's point ipsilateral to the side of stimulation, with low- and high-frequency filters at 5 and $3000 \mathrm{~Hz}$. An electrode at Fz was used as the common reference point. With Pathfinder II, 1024 or 2048 responses for each channel were averaged.

Square wave pulse electric stimulation of $0.1 \mathrm{~ms}$ duration at a rate of 2.7 per second was applied to the median nerve at wrist. Stimulation intensity was adjusted to the minimum current for eliciting visible thumb twitching. Right and left median nerve were tested separately.

For measurement, the absolute latencies of N1 (N20) component of scalp SEPs and Ni⿱3 peak of neck SEPs were recorded. Central conduction time (CCT) in the somato- sensory pathway was defined as the time differences between N1 latency of the scalp SEP and N13 latency of the neck SEP.

Scalp SEPs by stimulation of the peroneal nerve at the ankle were recorded at the vertex $(\mathrm{Cz})$, with a reference point at Fz. Filters were set at 1 and $3000 \mathrm{~Hz}$ and the analysis time was $200 \mathrm{~ms}$. Electric stimulation of $0.2 \mathrm{~ms}$ duration was delivered at a rate of $2 \cdot 1 / \mathrm{s}$ and its intensity was adjusted to induce visible twitching of the toes. Two hundred and fifty-six or 512 responses were averaged for each trial. Each leg was stimulated separately. For measurement, the absolute latency of P1 (P40) was selected.

In the normal controls, there were 25 males and 17 females, with a mean age of $36.9 \pm 9 \cdot 2$ years.

\section{Results}

All the results of evoked potentials presenting in the following tables were calculated by combining the findings obtained from the right side stimulation and those from the left side stimulation.

\section{Patterned visual evoked potentials}

Table 3 shows the absolute latencies of $\mathrm{N} 1, \mathrm{P} 1$, and N2 components of pVEPs. The N1-N2 interpeak latencies, the N1-P1 interpeak amplitude, and the P1-N2 interpeak amplitude are also listed in table 3. $\mathrm{N} 1, \mathrm{P} 1$, and $\mathrm{N} 2$ absolute latencies and N1-N2 interpeak latencies were significantly longer in the subclinical and polyneuropathy cases than in the normal controls and the unaffected workers. Significant decreases of N1-P1 and P1-N2 interpeak amplitudes were also found in polyneuropathy cases.

\section{Brainstem auditory evoked potentials}

Table 4 shows the absolute latencies of wave I, III, and $\mathrm{V}$ in the BAEP study. The I-III, III-V, and I-V interpeak latencies are also listed. There was no significant difference of wave I latency among the four groups $(F=0.5326, \alpha>0.13)$. The absolute wave III and V latencies, and the I-III, III-V and I-V interpeak latencies were significantly prolonged in the polyneuropathy cases. The tendency for the longer interpeak latencies to be associated with the more severe the involvement of the peripheral nerves can be observed in Table 4.

Table 3 Findings of patterned visual evoked potentials at a visual angle of $30^{\prime}$ in workers exposed to n-hexane

\begin{tabular}{|c|c|c|c|c|c|}
\hline & $\begin{array}{l}\text { Normal controls } \\
(n=44)\end{array}$ & $\begin{array}{l}\text { Unaffected workers } \\
(n=14)\end{array}$ & $\begin{array}{l}\text { Subclinical cases } \\
(n=10)\end{array}$ & $\begin{array}{l}\text { Polyneuropathy } \\
\text { cases }(n=44)\end{array}$ & $\begin{array}{l}\text { Statistically } \\
\text { significant levels }\end{array}$ \\
\hline $\begin{array}{l}\text { N1 latency }(\mathrm{ms}) \\
\text { P1 latency }(\mathrm{ms}) \\
\text { N2 latency }(\mathrm{ms}) \\
\text { N1-N2 interpeak latency }(\mathrm{ms}) \\
\text { N1-P1 interpeak amplitude }(\mu \mathrm{V}) \\
\text { P1-N2 interpeak amplitude }(\mu \mathrm{V})\end{array}$ & $\begin{array}{r}72 \pm 4 \\
96 \pm 3 \\
127 \pm 7 \\
55 \pm 5 \\
8 \cdot 00 \pm 3 \cdot 49 \\
9 \cdot 36 \pm 2 \cdot 85\end{array}$ & $\begin{array}{l}71 \pm 2 \\
96 \pm 3 \\
131 \pm 8 \\
60 \pm 9 \\
7.72 \pm 2.08 \\
9.52 \pm 3.84\end{array}$ & $\begin{array}{l}75 \pm 5 \\
102 \pm 7 \\
139 \pm 12 \\
65 \pm 10 \\
7 \cdot 51 \pm 1.35 \\
9.03 \pm 2.52\end{array}$ & $\begin{array}{l}75 \pm 5 \\
101 \pm 7 \\
138 \pm 12 \\
63 \pm 12 \\
5 \cdot 70 \pm 2 \cdot 85 \\
5 \cdot 58 \pm 2 \cdot 37\end{array}$ & $\begin{array}{l}\mathrm{t}=3.108, \mathrm{p}<0.005 \\
\mathrm{t}=4.355, \mathrm{p}<0.0005 \\
\mathrm{t}=5.252, \mathrm{p}<0.0005 \\
\mathrm{t}=4.082, \mathrm{p}<0.0005 \\
\mathrm{t}=3.386, \mathrm{p}<0.005 \\
\mathrm{t}=6.765, \mathrm{p}<0.0005\end{array}$ \\
\hline
\end{tabular}

Statistically significant levels were obtained from Student's $t$ test on "normal controls" versus "polyneuropathy cases". 
Table 4 Findings of brainstem auditory evoked potentials in workers exposed to n-hexane

\begin{tabular}{|c|c|c|c|c|c|}
\hline & $\begin{array}{l}\text { Normal controls } \\
(n=50)\end{array}$ & $\begin{array}{l}\text { Unaffected workers } \\
(n=14)\end{array}$ & $\begin{array}{l}\text { Subclinical cases } \\
(n=10)\end{array}$ & $\begin{array}{l}\text { Polyneuropathy } \\
\text { cases }(n=44)\end{array}$ & $\begin{array}{l}\text { Statistically } \\
\text { significant levels }\end{array}$ \\
\hline $\begin{array}{l}\text { Wave I latency (ms) } \\
\text { Wave III latency (ms) } \\
\text { Wave V latency (ms) } \\
\text { I-III interpeak latency (ms) } \\
\text { III-V interpeak latency (ms) } \\
\text { I-V interpeak latency (ms) }\end{array}$ & $\begin{array}{l}1.62 \pm 0.13 \\
3.70 \pm 0.15 \\
5.55 \pm 0.15 \\
2.08 \pm 0.12 \\
1.85 \pm 0.14 \\
3.94 \pm 0.16\end{array}$ & $\begin{array}{l}1.66 \pm 0.13 \\
3.82 \pm 0.15 \\
5.69 \pm 0.30 \\
2.16 \pm 0.26 \\
1.86 \pm 0.23 \\
4.02 \pm 0.25\end{array}$ & $\begin{array}{l}1.64 \pm 0.15 \\
3.90 \pm 0.25 \\
5.87 \pm 0.18 \\
2.27 \pm 0.16 \\
1.98 \pm 0.19 \\
4.25 \pm 0.30\end{array}$ & $\begin{array}{l}1.65 \pm 0.14 \\
3.93 \pm 0.26 \\
5.93 \pm 0.24 \\
2.29 \pm 0.18 \\
2.00 \pm 0.21 \\
4.28 \pm 0.21\end{array}$ & $\begin{array}{l}\mathrm{t}=1.077, \mathrm{p}>0.25 \\
\mathrm{t}=5.330, \mathrm{p}<0.0005 \\
\mathrm{t}=9.320, \mathrm{p}<0.0005 \\
\mathrm{t}=6.726, \mathrm{p}<0.0005 \\
\mathrm{t}=4.118, \mathrm{p}<0.0005 \\
\mathrm{t}=8.888, \mathrm{p}<0.0005\end{array}$ \\
\hline
\end{tabular}

Statistically significant levels were obtained from Student's t test on "normal controls" versus "polyneuropathy cases".

Table 5 Findings of somatosensory evoked potentials (SEPs) in workers exposed to n-hexane

\begin{tabular}{|c|c|c|c|c|c|}
\hline & $\begin{array}{l}\text { Normal controls } \\
(n=84)\end{array}$ & $\begin{array}{l}\text { Unaffected workers } \\
(n=14)\end{array}$ & $\begin{array}{l}\text { Subclinical cases } \\
(n=10)\end{array}$ & $\begin{array}{l}\text { Polyneuropathy } \\
\text { cases }\end{array}$ & $\begin{array}{l}\text { Statistically } \\
\text { significant levels }\end{array}$ \\
\hline $\begin{array}{l}\text { Scalp SEP latency by median N } \\
\text { stim (ms) }\end{array}$ & $18.44 \pm 0.80$ & $18.53 \pm 0.57$ & $19.40 \pm 0.95$ & \multirow{4}{*}{$\begin{array}{l}20.49 \pm 0.90 \\
(n=42) \\
14.30 \pm 0.78 \\
(n=42) \\
6.20 \pm 0.55 \\
(n=42) \\
45.37 \pm 3.68 \\
(n=40)\end{array}$} & $t=12.444, p<0.0005$ \\
\hline $\begin{array}{l}\text { Neck SËP latency by median N } \\
\text { stim (ms) }\end{array}$ & $12 \cdot 73 \pm 0.72$ & $12.72 \pm 0.71$ & $13.48 \pm 0.78$ & & $t=11.221, p<0.0005$ \\
\hline $\begin{array}{l}\text { Central conduction time by } \\
\text { median } \mathrm{N} \text { stim (ms) }\end{array}$ & $5.70 \pm 0.45$ & $5.81 \pm 0.49$ & $5.92 \pm 0.44$ & & $\mathrm{t}=5.451, \mathrm{p}<0.0005$ \\
\hline $\begin{array}{l}\text { Scalp SEP latency by peroneal N } \\
\text { stim (ms) }\end{array}$ & $39 \cdot 13 \pm 2 \cdot 45$ & $39.86 \pm 1.68$ & $42 \cdot 32 \pm 2.84$ & & $\mathrm{t}=11.199, \mathrm{p}<0.0005$ \\
\hline
\end{tabular}

Statistically significant levels were obtained from Student's t test on "normal controls" versus "polyneuropathy cases".

\section{Somatosensory evoked potentials}

In one polyneuropathy patient, no identifiable SEPs could be elicited by electric stimulation of either the median or the peroneal nerve. In another patient, scalp SEPs could not be obtained by peroneal nerve stimulation.

Table 5 shows the scalp and neck SEP latencies obtained by stimulation of the median nerve, and the scalp SEP latencies by stimulation of the peroneal nerve. Central somatosensory conduction time (CCT), which was calculated by subtracting the neck SEP latency from the scalp SEP latency by stimulation of the median nerve, is also listed. All the SEP latencies and CCT in subclinical and polyneuropathy cases were significantly longer than those in the normal controls. There was a tendency to have longer SEP latencies and CCT with increasing severity of peripheral nerves involvement.

\section{Discussion}

Acute exposure to high air concentration of $n$-hexane can induce nausea, headache, giddiness, euphoria, hallucination, and mild narcosis. ${ }^{1}$ Sensorimotor polyneuropathy is the principal neurological manifestation in subacute or chronic exposure to $n$ hexane, although cranial neuropathies, blurred vision, and abnormal colour vision associated with macular changes have also been reported. ${ }^{6810-12}$ During the initial neurological evaluation of the patients with n-hexane polyneuropathy, symptoms and signs indicating CNS involvement were often not obvious. Sobue et $a l^{6}$ reported $35 \mathrm{n}$-hexane polyneuropathy patients among vinyl sandal manufacturers and found that except for irritability, dizziness, or sleeplessness, there was no evidence of CNS involvement. In a detailed clinical investigation of 93 patients with n-hexane polyneuropathy, Yamamura ${ }^{10}$ concluded that there were no symptoms and signs indicating lesions in CNS.

Pathologically, giant axonal swelling with dying back degeneration is the main finding in sural nerve biopsies from $\mathrm{n}$-hexane polyneuropathy patients and in experimental hexacarbon polyneuropathy. ${ }^{1}$ However, besides the peripheral nerves, axonal swelling, axonal degeneration, and secondary breakdown of myelin sheath was also observed in the CNS in experimental animals intoxicated with hexacarbon. In rats, Spencer and Schaumburg $^{3}$ found that the long ascending and descending tracts of the spinal cord were affected first. The same pathological changes in the cerebellum and lateral geniculate body were also present in rats with advanced disease. ${ }^{3}$ In cats intoxicated by low-level but prolonged administration of 2,5-hexanedione (the putative neurotoxic metabolite of n-hexane), Schaumburg and Spencer ${ }^{4}$ demonstrated early axonal swellings in the mammillary bodies, the lateral geniculate body and distal optic tract, and the superior colliculi. In view of these pathological studies, it is not unreasonable to postulate that there may be simultaneous CNS lesions in $n$-hexane polyneuropathy patients. 
Neurotoxic effects of $n$-hexane on the human central nervous system:evoked potential abnormalities in polyneuropathy

Although there is an absence of clear clinical signs of CNS degeneration at the initial neurological evaluations in patients with $\mathrm{n}$-hexane polyneuropathy, indirect evidence indicating CNS involvement has been mentioned on follow-up studies. After recovery of muscle strength and sensation, the patients may have residual spasticity and hyperactive tendon reflexes, ${ }^{15813}$ suggesting irreparable damage to the long tracts of the spinal cord. Schaumburg and Spencer $^{4}$ thought that weakness and sensory impairment associated with peripheral nerves damage would mask signs of CNS degeneration.

In addition to bedside neurological examination, electrophysiological techniques have also been employed to evaluate the neurotoxic effects of nhexane on the CNS. By studying H-reflex behaviour in patients with $\mathrm{n}$-hexane polyneuropathy, Bravaccio et $a l^{13}$ found that an increased excitability of alpha motorneurons in their patients gave good evidence of spinal cord involvement. After analysis of scalp SEPs by stimulation of the median nerves, Mutti et al $^{14}$ noted much flatter later SEP components in 15 women exposed to $n$-hexane than in the control group, suggesting some neurotoxic effects of $n$-hexane on the CNS. Seppalainen et al ${ }^{1215}$ found abnormal amplitudes and latencies of flash visual evoked potentials in industrial workers exposed to n-hexane. They interpreted these changes as the result of cerebral dysfunction, probably conduction block in intracerebral axons.

In the present study, the N1, P1 and $\mathrm{N} 2$ absolute latencies, and N1-N2 interpeak latency of patterned VEP were longer in both the subclinical and polyneuropathy groups than in the normal controls and unaffected workers. Although maculopathy and colour discrimination defects are the main eye findings in industrial workers exposed to n-hexane, ${ }^{1215}$ they usually do not induce latency abnormalities of the patterned VEP. ${ }^{16}$ Optic nerve atrophy and retrobulbar neuritis, which can cause abnormalities in patterned VEP and have been reported in patients with $\mathrm{n}$-hexane polyneuropathy, ${ }^{10}$ were not found in the present study (table 2 ). Therefore, the pVEP abnormality shown in table 3 cannot be explained by the toxic effects of $n$-hexane on the retina or visual pathway peripheral to the geniculate bodies. As P1 of patterned VEP is generated in the primary visual cortex but probably does not represent the first cortical component, ${ }^{16}$ the latency abnormalities in the subclinical and polyneuropathy groups result from cerebral dysfunction. Cerebral dysfunction could also be responsible for the amplitude attenuation in the polyneuropathy patients, although the role of maculopathy in amplitude changes is not clear.

In the BAEP study, I-III, III-V, and I-V interpeak latencies reflect neural conduction in the correspond- ing segments of the central auditory pathway in the brainstem. In the present study, the lack of difference of wave I latency between the normal controls and factory workers suggests that the auditory nerve itself was not severely affected in $\mathrm{n}$-hexane intoxication. Prolongation of interpeak latencies in subclinical cases and polyneuropathy patients should be interpreted as neurotoxical effects of $n$-hexane on the brainstem.

Slow conduction in the peripheral nerves can partly explain the delay of the scalp SEP and neck SEP latencies in patients with n-hexane polyneuropathy. Prolongation of the central somatosensory conduction time as shown in the present study is the other crucial factor for the delay of SEP latencies. As the impulses for eliciting scalp SEPs are transmitted through the posterior columns of the spinal cord, and early pathological changes involving the rostral part of the gracile and cuneate tracts have been found in experimental rats intoxicated by n-hexane, ${ }^{13}$ it is not surprising that there is abnormally prolonged central somatosensory conduction time in patients with nhexane polyneuropathy. This is electrophysiological evidence of neurotoxic effects of $n$-hexane on the spinal cord and/or the brainstem.

In analysing evoked potential abnormalities, subject variables which may influence the latency and amplitude of evoked potentials should be considered. Aging has often been reported to increase the absolute and interpeak latencies, and to decrease the amplitude. ${ }^{17}$ In the present study, the mean ages of each worker group were younger than that of normal controls, hence, there would be much more abnormality if the evoked potential results were ageadjusted. Sex differences have been mentioned in the absolute P1 latency of patterned VEPs and interpeak latencies of BAEPs, ${ }^{17}$ yet have not been observed in central somatosensory conduction time. ${ }^{18}$ Sex differences were considered negligible in the present study, for there was only one female subject in each worker group.

From the results of the evoked potential study, it is concluded that there are chronic neurotoxic effects of n-hexane on the central nervous system, including the cerebrum, the brainstem, and the spinal cord. These toxic effects exist in patients with clinical or subclinical polyneuropathy, and also possible in exposed workers without abnormal nerve conduction velocities in the peripheral nerves.

\section{References}

I Spencer PS, Couri D, Schaumburg HH. n-Hexane and methy n-butyl ketone. In: Spencer PS, Schaumburg $\mathrm{HH}$, eds. Experimental and Clinical Neurotoxicology. Baltimore: Williams \& Wilkins, 1980:456-75. 
2 Scelsi R, Poggi P, Fera L, Gonella G. Industrial neuropathy due to n-hexane-clinical and morphological findings in three cases. Clin Toxicol 1981;18:1387-93.

3 Spencer PS, Schaumburg HH. Ultrastructural studies of the dying-back process, IV. Differential vulnerability of PNS and CNS fibers in experimental centralperipheral distal axonopathies. J Neuropathol Exp Neurol 1977;36:300-20.

4 Schaumburg HH, Spencer PS. Environmental hydrocarbons produce degeneration in cat hypothalamus and optic tract. Science 1978;199:199-200.

5 Schaumburg HH, Spencer PS. Clinical and experimental studies of distal axonopathy - a frequent form of brain and nerve damage produced by environmental chemical hazards. Ann NY Acad Sci 1979;329:14-29.

6 Sobue I, Yamamura Y, Ando K, Iida M, Takayanagi T. n-Hexane polyneuropathy-outbreak among vinyl sandal manufacturers. Clin Neurol (Jpn) 1968;8: 393-403.

7 Matsumura M, Inoue N, Ohnishi A, Santo T, Goto I. Toxic polyneuropathy due to glue-sniffing. Clin Neurol (Jpn) 1972;12:290-6.

8 Korobkin R, Asbury AK, Summer AJ, Nielsen SL. Glue-sniffing neuropathy. Arch Neurol 1975;32: 158-62.

9 Wang JD, Chang YC, Kao KP, Huang CC, Lin CC, Yeh WY. An outbreak of $n$-hexane induced polyneuropathy among press proofing workers in Taipei. Am J Industrial Med 1986;10:111-8.
10 Yamamura Y. n-Hexane polyneuropathy. Fol Psychiat Neurol (Jpn) 1969;23:45-57.

11 Gonzalez E, Downey J. Polyneuropathy in a glue sniffer. Arch Phys Med 1972;53:333-7.

12 Seppalainen AM, Raitta C, Huuskonen MS. Nervous and visual effects of occupational n-hexane exposure. In: Lechner $\mathrm{H}$, Aranibar A, eds. EEG and Clinical Neurophysiology. Amsterdam: Excerpta Medica 1980:656-61.

13 Bravaccio F, Ammendola A, Barruffo L, Carlomagno S. $\mathrm{H}$-reflex behavior in glue (n-hexane) neuropathy. Clin Toxicol 1981;18:1369-75.

14 Mutti A, Ferri F, Lommi G, Lotta S, Lucertini S, Franchini $I$. n-Hexane-induced changes in nerve conduction velocities and somatosensory evoked potentials. Int Arch Occup Environ Health 1982;51:45-54.

15 Seppalainen AM, Raitta C, Huuskonen MS. n-Hexaneinduced changes in visual evoked potentials and electroretinograms of industrial workers. Electroencephalogr Clin Neurophysiol 1979;47:492-8.

16 Lueders H, Lesser RP, Klem G. Pattern evoked potentials. In: Henry CE, ed. Current Clinical Neurophysiology: Update on EEG and Evoked Potentials. New York: Elsevier/North Holland 1980:467-525.

17 Spehlmann R. Evoked Potential Primer. Boston: Butterworth Publishers, 1985:98-9, 208 \& 297.

18 Chang YC. Influences of age and body height on central somatosensory conduction time in normal subjects. J Formosan Med Assoc 1984;83:912-21. 